\title{
LNG: an alternative fuel for road freight transport in Europe
}

\author{
J. Osorio-Tejada, E. Llera \& S. Scarpellini \\ CIRCE - Centre of Research for Energy Resources and Consumption, \\ University of Zaragoza, Spain
}

\begin{abstract}
Currently, energy consumption in the worldwide transport sector depends on $92.8 \%$ oil fuels. This dependency, among other problems, produces high levels of harmful emissions, which makes it necessary to increase the use of less polluting and more cost-effective alternative sources as natural gas. Furthermore, this alternative fuel must have autonomy, security and as optimal storage volume as the natural gas use in liquid state. This paper reviews the liquefied natural gas (LNG) use advantages over other fuels and analyses its introduction prospects in the transport sector in Europe, specifically in road freight transport. Natural gas (NG) technology for transportation is mature and extended through the compressed use $(\mathrm{CNG})$ in urban light vehicles. However, $\mathrm{CNG}$ has not been attractive for extra-urban use mainly by the limited energy storage volume and difficulties for NG stations installation. For this problem, a LNG vehicle with the same fuel tank size could travel up to 2.4 times the distance compared with CNG. LNG in heavy-duty trucks reduces GHG emissions per kilometre up to $20 \%$ and almost $100 \%$ SOx and particulate matter, as well the noise in inner cities, compared to diesel trucks. An additional advantage is the operation cost savings that would give a LNG conversion payback between 1 and 3 years. The European Union has promoted the construction of LNG stations by the TEN-T programme and projects as the 'LNG Blue Corridors' in order to create a road network with LNG stations each $400 \mathrm{~km}$. In addition, the world natural gas reserves would ensure the energy supply for the transport sector in Europe. Hence, the LNG for road freight transport is a potential alternative to replace the traditional fuels in the short to medium term.

Keywords: LNG, liquefied natural gas, freight transport, heavy-duty vehicle.
\end{abstract}




\section{Introduction}

For decades, global energy supply has depended on oil, which was about $32.9 \%$ of total primary energy consumption in 2013 [1]. The high share of oil means elevated greenhouse gases ( $\mathrm{GHG})$ emissions levels $\left(\mathrm{CO}_{2}, \mathrm{CH}_{4}\right.$ and $\left.\mathrm{N}_{2} \mathrm{O}\right)$, and toxic emissions such as $\mathrm{CO}, \mathrm{NO}_{\mathrm{x}}$, NMVOCs (Non-methane volatile organic compounds), $\mathrm{SO}_{\mathrm{x}}$ and particulate matter (PM). These emissions are mainly produced by the transport sector, where about $92.8 \%$ of the energy consumption came from gasoline and diesel in 2012 [2].

The transport sector in Europe (EU-15) released 21\% of total GHG emissions in 2012 , and about $94 \%$ of these emissions were provided by road transport. In this transport mode, the use of gasoline and diesel yielded $98 \%$ of GHG emissions (700.5 $\mathrm{Mt} \mathrm{CO}_{2 \text {-eq) [3]. }}$ [3

Therefore, it is necessary to use less polluting and cost-effective alternative sources for replacing oil fuels as natural gas (NG) [4]. In Europe, NG has been considered an alternative to replace conventional fuels (gasoline and diesel) mainly for reducing the environmental impact and for reaching the European Union (EU) goal concerning to replace $20 \%$ of conventional fuels used for road transport by 2020 , which was proposed in the Green Paper on security of energy supply in 2001. For that time, the EU planned the introduction of biofuels in the short and medium term, natural gas in the medium and long term and hydrogen in a distant long term [5]. Currently, biofuels share about 5\% in the road transport fuels in Europe, however, after observing difficulties to expand its application as the competition with the agricultural sector, the EU aims to maintain this percentage of biofuels and encourage other alternative sources [6]. The European Parliament and the Council, with its directive 2014/94/EU on the deployment of alternative fuels infrastructure, regarding the Commission communication 'Clean Power for Transport', set deadlines for Member States to define the regulations and ensure an appropriated number of refuelling stations for road vehicles. Among these targets, the directive sets for electricity and CNG stations in urban and suburban densely populated areas, a deadline by the end of 2020. For the installation of LNG stations through roads and ports that connect the Trans-European Network for Transport (TEN-T Core Network) to supply heavy-duty vehicles (HDVs) and, for the Member States that decide to include hydrogen stations, the deadline is by the end of 2025. Likewise, the EU aims that these natural gas stations can receive biomethane blends produced locally for decrease the carbon intensity in the fossil natural gas [7].

The EU strategy for the alternative fuels is developed by the priority of proceeding with mature technologies for each need. For short distances in urban areas there are several suitable alternatives as $\mathrm{CNG}$, electricity and hydrogen, while for long distance transport, the only viable and mature alternative for diesel substitution is LNG [8].

The feasibility of implementing the use of LNG in HDVs is evident because of its higher energy density, which gives superior autonomy versus CNG [9]. During the LNG production, the natural gas is dehydrated and cleaned of hydrocarbons, $\mathrm{CO}_{2}$ and sulphur [10], obtaining a high purity of methane (98\%), 
then cooled to $-162^{\circ} \mathrm{C}$, becoming a liquid and reducing its volume 600 times approximately. The energy density of LNG is $435 \mathrm{~kg} / \mathrm{m}^{3}$ while for $\mathrm{CNG}$ is $175 \mathrm{~kg} / \mathrm{m}^{3}$ at 200 bar; this means that a LNG vehicle with the same fuel tank size could travel up to 2.4 times the distance compared with CNG $[11,12]$.

Due to the high purity of the LNG, the toxic engine emissions compared with the use of traditional fuels are lower; about $80 \% \mathrm{CO}, 70 \% \mathrm{NO}_{\mathrm{x}}$ and $45 \%$ of NMVOCs, while $\mathrm{SO}_{\mathrm{x}}$ and $\mathrm{PM}$ the reduction is greater than $97 \%[11,12]$. In terms of energy consumption ( $\mathrm{g} \mathrm{CO}_{2}$-eq/MJ), the $\mathrm{LNG}$ combustion analysis in the vehicle or Tank-To-Wheels (TTW), shows reductions of GHG emissions up to $25 \%$. However, as a result of the extra-energy needed for liquefaction, transportation and distribution of LNG compared to diesel in the Well-To-Tank (WTT) analysis, for the fuel life-cycle assessment or Well-to-Wheels (WTW), which consist of the WTT plus the TTW analysis, the total GHG emissions reduction would be up to $16 \%$ [13-16]. Furthermore, LNG engines are less efficient than modern diesel engines; namely, LNG engines consume more energy per kilometre. There are two kinds of LNG engines: the "dual fuel", which uses compression ignition (CI) engine with $90-95 \%$ LNG and the rest diesel as pilot, is only by $0 \%$ to $5 \%$ less efficient; while in a "dedicated", which uses spark ignition (SI) engine with $100 \%$ LNG, the efficiency is about $10 \%$ to $30 \%$ lower $[17,18]$, resulting in a lower emission reduction. Hence, in the TTW analysis, the reduction of GHG emissions per kilometre is up to $20 \%[13,15$, 19-22], while the WTW analysis can show both reductions and increases up to $10 \%$, that is to say, a variation between $-10 \%$ and $10 \%$ in total GHG emissions per kilometre compared to the diesel emissions [15, 20, 23, 24].

Nevertheless, the LNG would be a good alternative for freight transport; Litzke and Wegrzyn [25] said that LNG could directly replace diesel for all types of trucks. Andress et al. [26] stated that using LNG in road freight transport in the U.S. generates modest impacts on GHG reduction, but it can diversify the fuel used in HDVs, where diesel is used in almost $100 \%$ of trucks. Kumar et al. [11], in a review of the LNG uses including HDVs, affirmed LNG is "an ecofriendly fuel". However, most studies about LNG application in heavy-duty trucks have been developed in countries abroad Europe, especially in North American and Asian countries; therefore, there is not enough research for developing a reliable database to estimate the actual impact of LNG on the European scenario.

\section{Fuels for road transport}

After the 1973 petroleum crisis, countries have been intensifying the search of economic and cleaner fuels for the transport sector, such as hydrogen, biofuels, electricity, natural gas, synthetic fuels from coal, among others.

The use of hydrogen $\left(\mathrm{H}_{2}\right)$ as fuel can significantly reduce GHG emissions, but the problem for the $\mathrm{H}_{2}$ introduction is the high production costs and the low density, requiring large investments to maintain the security and acceptable energy storage [27]. For the electric car with energy storage in batteries, there are problems such as the time for recharging, the low autonomy, the high cost 
and mass; therefore, electric vehicles are more suitable for urban use or short distances [4].

In the case of biofuels, especially bioethanol and biodiesel, the main problem is their limited availability, due to the land use competition that is dedicated for food production. Synthetic fuels (liquid and gaseous fuels from coal) have high availability; however, the methods that allow a cleaner life cycle such as the $\mathrm{CO}_{2}$ capture increase the costs of the final product. In the long term, if more efficient production processes are achieved, gaseous fuels from coal could be used as long as the number of gas-powered vehicles has increased considerably [28].

The European Union and several authors have presented the natural gas as the best alternative for road transport in the short to medium term in order to reduce the environmental impact generated by this transport mode. Natural gas has been widely applied in light and heavy-duty vehicles, three-wheelers, even in ships, planes and trains. The main factors for governments to promote natural gas use in vehicles are the environmental benefits of reducing local air pollution, the resource availability, the existence of pipelines and distribution infrastructure and the oil dependency reduction [29].

The natural gas in vehicles was introduced in Italy in 1930, while New Zealand also took accelerated steps years later [30]. In other world regions, the number of NG vehicles has increased after 1980, especially in Latin America and Asia, where the main reason has been the cost savings due to the indigenous natural gas use. In some of these countries, up to $20 \%$ of the entire fleet work with natural gas. In contrast, in Italy, the European country with most experience in NG vehicles, they share only $1.1 \%$ of the entire registered fleet [11].

The NG use is currently mature and extended by the CNG application in light SI engines for urban use. However, Chen et al. (2009) and Meng (2010) (cited in [10]) argued that the main problem of CNG vehicles is their autonomy that is about $150 \mathrm{~km}$, because of its limited energy storage capacity. Consequently, for long distances is undesirable, because $\mathrm{CNG}$ vehicles would require a refuelling station at least each $100 \mathrm{~km}$, which is difficult to implement due to low demand of NG vehicles in Europe. Therefore, in recent years the use of LNG for freight transport is presented as the solution to these obstacles.

\section{LNG for road freight transport}

The high energy density of LNG for use in HDVs is an advantage that has been evaluated in different kinds of trucks; e.g. a dump truck BelAZ-75485, with a LNG 560-liter fuel tank, stores the equivalent of 25 to 27 CNG cylinders, saving $2000 \mathrm{~kg}$ of carrying capacity [31]. Lu et al. [32] reported that a LNG bus in Beijing with a 335-litre fuel tank could travel $450 \mathrm{~km}$ without stopping to recharge, and Zhou et al. [33] affirmed that a LNG truck for freight transport between the U.S. and Canada, with a 680-litre fuel tank could travel $800 \mathrm{~km}$. Another advantage is that the LNG recharge time is only $1 / 3$ to $1 / 5$ compared to CNG vehicles [10]. Currently, different manufacturers offer trucks with LNG engines dual fuel or dedicated having autonomy of up to $1100 \mathrm{~km}$ [17]. 
The application of LNG in vehicles is supported by the mature technology for the natural gas combustion, because in CNG and LNG vehicles the fuel is always injected in the engine in gaseous form. Thus, the main difference in both kinds of vehicles is the fuel storage method. In a LNG vehicle with either CI or SI engine, according to Lu et al. [32], the cryogenically stored natural gas is preheated and vaporized in a heat exchanger (usually with the engine radiator fluid) before being injected in gaseous form to the cylinders for being burned at a temperature between $-40^{\circ} \mathrm{C}$ and $90^{\circ} \mathrm{C}[10]$.

As mentioned at the beginning, LNG trucks produce low toxic emissions; therefore, they can seamlessly fulfil the Euro 6 standard without requiring aftertreatment exhaust equipment, as is required by diesel trucks. However, if the $\mathrm{LNG}$ engine has no right setup, it could increase emissions of $\mathrm{NO}_{\mathrm{x}}$ and unburned methane, which must be controlled by an exhaust gas recirculation valve (EGR) correctly installed [34]. Currently, there are no predetermined emission factors to estimate how much gases will emit certain type of LNG-fuelled truck running by specific road, because emissions depend on variables such as engine and local temperature, altitude above sea level, engine condition and mileage, emission control technology, fuel purity, driving mode, as well as the vehicle load, which can increase the exhaust emissions about 45\% [35]. For these reasons, several studies have reported different reduction rates related to GHG emissions per kilometre for TTW analysis, as well as for WTT analysis due to the diverse ways and methods for disposing the LNG in the refuelling stations; e.g. imported or indigenous NG and pipeline or trucking distribution. A WTW analysis compilation from literature, considering only LNG imported by sea and carried from regasification terminal to the LNG station by tanker truck is illustrated in fig. 1 .

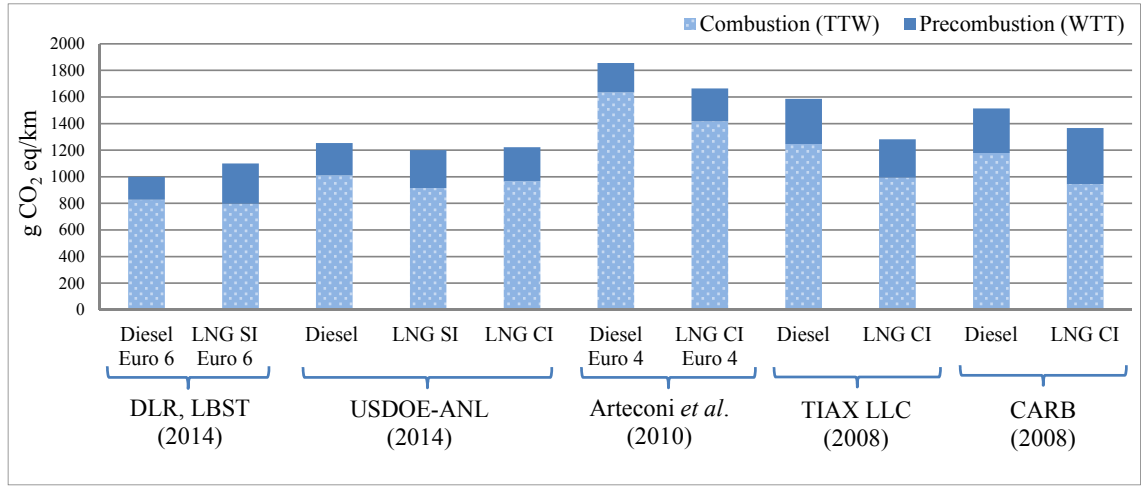

Figure 1: Life-cycle GHG emissions' comparison in LNG and diesel HDVs. Sources: author's compilation from [13-15, 17, 22, 23].

In the medium to long term, using liquefied synthetic methane, produced by synthesis of $\mathrm{CO}_{2}$ and $\mathrm{H}_{2}$ with renewable electricity (Power-To-Gas), or using 
liquefied biomethane, the GHG emissions per kilometre could decrease up to $92 \%$ and $62 \%$, respectively [17].

In addition to the potential use of LNG in road transport in order to reduce pollutant emissions, an additional advantage is the cost savings, due to the lower LNG price compared to diesel. In the U.S., where there are around 3600 LNG trucks, a study published in 2015 found that because of the extra cost of a new LNG truck, traveling over $192000 \mathrm{~km}$ each year, the payback would be less than 3 years [18]. In China, for an engine converted to LNG, the payback is less than 2 years, according to estimations made in 2013 [34]. For the European case, Spanish transport companies which had 182 LNG trucks by the end of 2013, have reported a payback between 1 and 2 years [37, 38].

\subsection{LNG supply at service stations}

By the end of 2014, Europe only had 43 LNG stations, which 90\% of these were concentrated in Spain, Netherlands, United Kingdom and Sweden [39]. One of the factors for the slow growth of LNG use in HDVs is the lack of refuelling stations across European countries. Some surveys cited by Yeh [29] suggested that people would be interested in natural gas vehicles if at least between $10 \%$ and $20 \%$ of conventional stations could offer NG.

Without government intervention, the number of LNG stations will grow as the market for LNG-powered vehicles increase, and vice versa, falling into a chicken and egg problem which alternative fuels have challenged [18].

For the LNG supply in stations there are two options: liquefaction "in-situ", namely, liquefaction process in small scale at the service station using NG from pipeline; or carrying the LNG by tanker trucks from a regasification terminal to the service station, which has been considered as the most profitable option in many studies [10]. A study in Italy reported that carrying the LNG by ship from the Barcelona regasification terminal (800 km away from the Italian coast) and then by tanker truck to service stations in Italy, is less expensive than performing liquefaction in-situ, even if the regasification terminal is up to $2000 \mathrm{~km}$ away [9].

Another advantage, because of the higher density of LNG compared with $\mathrm{CNG}$, the LNG station does not need gas compressor, consequently is more compact and less noisy [10]. To remove the barrier of limited LNG stations, in addition of promoting the installation of alternative fuel stations by the TEN-T programme, the EU has also created specific projects such as the "LNG Blue Corridors" with the target to build 14 new LNG stations and a fleet of 100 LNG HDVs for operating along the corridors [39]. Besides, in the short term the Mediterranean Sea would enter to the 'Emission Control Area', where ships must use cleaner fuels to reduce emissions, where LNG is among the most feasible alternatives, being necessary to develop LNG infrastructure in ports that will be able to encourage the use of this fuel for freight trucks [9].

\subsection{Impact on urban delivery}

Urban planning administrators perceive the urban freight transport negatively, because HDVs affect the mobility, the infrastructure and pollute the city. 
Although HDVs represent only $10 \%$ of vehicles operating in urban areas, they generate more than $40 \%$ of emissions and noise [40]. The World Health Organization stated that the noise is the second problem after toxic emissions generated by vehicles [41]. Thus, local governments choose to set restrictions to prevent delivery trucks running on certain areas or during peak hours. The restrictions are time-windows, access restrictions (by type of vehicle, emissions factor, size or mass), special zones and parking spaces for delivery vehicles, charge systems (tolls or maximum entries number), early/night deliveries, special urban planning conditions and alternative delivering [42]. Some companies decide to fulfil with the time-windows to deliver during the day hours but they reduce the delivery efficiency due to the higher number of trips at different times and partial load [43]. Companies also choose to increase the fleet with smaller vehicles; however, these vehicles require many person-hours to drive and in many cases must make several trips to the same place, increasing emissions, fuel consumption and congestion [44]. Therefore, the best alternative when companies have to bring many goods to one place, e.g. supermarkets, large factories and distribution centres, is to use a large capacity truck during the night.

Night delivery would decrease congestion and noise during the peak hours and would enhance the speed and efficiency. However, the night delivery is in conflict with the regulations regarding noise $[45,46]$. In Spain, in most cities, the night distribution is prohibited except in specific cases with special and very restricted permits [47]. It is here where natural gas trucks have an advantage over conventional trucks, since due to the high octane number, methane has high resistance to auto-ignition that increases the compression ratio and besides generating great thermal efficiency [34, 45, 49], reduces the engine noise compared to the diesel combustion $[50,51]$. Therefore, the use of NG fuelled buses and trucks can reduce both the concentration of pollutant emissions and noise in urban areas [4]. The ban on driving delivery trucks at night in Spanish cities has generated that transport companies equip their fleets with NG-powered engines. For example, the company 'Trio logistics operators', to supply the Simply supermarket, has two Mercedes-Benz Econic trucks fuelled with CNG, one for distribution in Madrid and the other in Zaragoza [52], both for local delivery because of theirs autonomy of $350 \mathrm{~km}$. While the company Acotral to supply the Mercadona supermarket has since late 2009 a same Econic truck but the LNG version that lets it traveling 800 to $1000 \mathrm{~km}$ without refuelling, hence, it is possible to deliver to several cities in one route. Companies, with LNG trucks and special permits from the cities' council for night delivery, would reduce GHG emissions by $20 \%$ and noise by $50 \%$ compared to diesel trucks [53].

\section{Prospects for the LNG introduction in the European scenario}

The LNG use as alternative fuel for road freight transport has different strengths compared to diesel, mentioned in this paper, such as the lower fuel cost, acceptable autonomy, lower emissions (mainly $\mathrm{SO}_{\mathrm{x}}, \mathrm{PM}$ and $\mathrm{NO}_{\mathrm{x}}$ without 
requiring after-treatment exhaust equipment), lower noise and mature application technology. Nevertheless, the LNG use in HDVs has weaknesses as the high cost of technology especially dual fuel engines and modest GHG emissions reduction due to leakage of methane during the LNG life cycle. In addition, LNG presents threats to their massive and commercial introduction, as the absence of regulation for installing service stations and restrictions for the LNG use in vehicles, the decline in the diesel price and the shortage risk of imported natural gas that would increase at once the LNG price in Europe.

Despite the above, the LNG introduction as a fuel in Europe has a favourable outlook. With the support from the EU for the development of infrastructure for LNG trucks by 2025 , and the government incentives for the purchase, fleet renewal and engine conversion to LNG operating, the market will grow and the manufacturers will be able to reduce prices for both new vehicles and conversion kits, as well as the efficiency combustion is expected to improve. To achieve greater GHG reductions throughout the LNG life cycle, in October 2014 the European Commission adopted the 'Fuel Quality Directive' for requiring to the fuel distributors for road transport to reduce by $6 \%$ the GHG intensity by 2020 [54], which will require taking measures to minimize leakage of methane. The shortage risk and the low diesel price do not bring concerns due to increased production and reserves of NG around the world, especially in the U.S. with shale gas. The U.S. plans to start the shale gas exportation by the end of 2015, which could reduce the NG market price. Worldwide conventional NG reserves are around 185.7 trillion $\mathrm{m}^{3}$ for 55.1 years [1]. The NG reserves, adding the commercially exploitable non-conventional sources (shale gas, tight gas and coal-bed methane), would be 638 trillion $\mathrm{m}^{3}$, and including the other nonconventional sources as aquifer gas and gas hydrates (Japan's Methane Hydrate R\&D program set commercial production would start by the end of 2018) [55], the amount would increase to 845 trillion $\mathrm{m}^{3}$ [56]. As a result, the European NG market would have supplier diversity, increasing energy security and competitive prices. Moreover, for receiving LNG from different suppliers by sea, Europe has 23 regasification terminals in operation which in 2014 worked on average $16 \%$ of installed capacity, namely, there is enough import potential, not to mention the 5 terminals under construction and 22 more that are planned to be built [57].

\section{Conclusions}

The LNG use in heavy-duty trucks for freight transport is possible due to a mature technology and energy resource availability. The LNG introduction in road transport in Europe, in addition of reducing the environmental impact and noise in cities, can improve the competitiveness of transport companies and decrease the price of goods because of lower logistics costs. The EU has a clear vision of encouraging the use of LNG by supporting the service stations construction along corridors connecting the Member States. Governments should intervene with means to encourage consumers directly, such as tax reduction, benefits in tolls, reduced import tariffs for conversion kits and new vehicles, and subventions for the development and manufacture of these technologies locally. 
In Europe there are no defined emission factors for LNG trucks that can be applied reliably to the European scenario, as a methodology that considers European environment and driven cycles for different kinds of heavy-duty trucks with diverse loads and road types, for being used by researchers for their LNG life-cycle analysis and simulations. For that reason, it is necessary to increase the experimentation for creating tools that facilitate the decision making for politicians, managers and stakeholders in Europe.

\section{References}

[1] British Petroleum, BP Statistical review of world energy. BP Statistical Review of World Energy, London, 2014.

[2] International Energy Agency (IEA), Key world energy statistics, Chirat: París, 2014.

[3] European Environment Agency, Annual European Union greenhouse gas inventory 1990-2012 and inventory report 2014, Copenhagen, 2014.

[4] H. Engerer and M. Horn, Natural gas vehicles: An option for Europe. Energy Policy, 38, pp. 1017-1029, 2010.

[5] Commission of the European Communities, WHITE PAPER. European policy for 2010: time to decide, Brussels, 2001.

[6] European Commission, EU launches clean fuel strategy, Press release, Brussels, 2013.

[7] European Parliament and the Council of the European Union, Directive 2014/94/EU of the European Parliament and the Council of 22 October 2014 on the deployment of alternative fuels infrastructure. Official Journal of the European Union, 57 (L 307), 2014.

[8] European Commission, Clean Power for Transport: A European alternative fuels strategy, Brussels, 2013.

[9] A. Arteconi and F. Polonara, LNG as vehicle fuel and the problem of supply: The Italian case study. Energy Policy, 62, pp. 503-512, 2013.

[10] L. Ma, J. Geng, W. Li, P. Liu and Z. Li, The development of natural gas as an automotive fuel in China. Energy policy, 62, pp. 531-539, 2013.

[11] S. Kumar, H.-T. Kwon, K.-H. Choi, W. Lim, J. H. Cho and K. Tak, LNG: An eco-friendly cryogenic fuel for sustainable development. Applied energy, 88, pp. 4264-4273, 2011.

[12] E. B. Fedorova, V. V. Fedorov and A. D. Shakhov, Promising technology for recovery and use of liquefied natural gas. Chemical and Petroleum Engineering, 45, pp. 18-21, 2009.

[13] California Air Resource Board (CARB), Comparison of greenhouse gas emissions from natural gas and diesel vehicles. Report 08/10/2008.

[14] DLR, ifeu, LBST \& DBFZ, LNG as an alternative fuel for the operation of ships and heavy-duty vehicles: Short study in the context of the National Mobility and Fuel Strategy, Federal Ministry of Transport and Digital Infrastructure (BMVI), Munich/Ottobrunn, 2014. 
[15] USDOE - Argonne National Laboratory, The Greenhouse Gases, Regulated Emissions, and Energy Use in Transportation Model, 03 October 2014. www.greet.es.anl.gov/

[16] JEC, Well-to-Wheels Analysis of Future Automotive Fuels and Powertrains in the European Context; Version 4a; Report EUR 26237 EN, April 2014, JEC - Joint Research Centre - EUCAR-CONCAWE collaboration, 2014.

[17] German Energy Agency (DENA), LNG in Germany: Liquefied Natural Gas and Renewable Methane in Heavy-Duty Road Transport, Aschersleben: Druckerei Mahnert GmbH, 2014.

[18] A. M. Jaffe, R. Dominguez-Faus, A. Lee, K. Medlock, N. Parker, D. Scheitrum, A. Burke, H. Zhao and Y. Fan, NextSTEPS White Paper: Exploring the Role of Natural Gas in U.S. Trucking, 18 February 2015. www.steps.ucdavis.edu/files/02-18-2015-NextSTEPS-White-PaperNatural-Gas-in-US-Trucking-18Feb2015-Public-Release.pdf

[19] L. A. Graham, G. Rideout, D. Rosenblatt and J. Hendren, Greenhouse gas emissions from heavy-duty vehicles. Atmospheric Environment, 42, pp. 4665-4681, 2008.

[20] M. A. Maimoun, D. R. Reinhart, F. T. Gammoh and P. M. Bush, Emissions from US waste collection vehicles. Waste Management, 33, pp. 1079-1089, 2013.

[21] Battle of the trucks; Rolande LCNG, Iveco Schouten. 2015. www.battleofthetrucks.nl/

[22] J. Rosenfeld and M. D. Jackson, Life-cycle cost model and pollutant emissions estimator. Report prepared for Westport Innovations Inc. by Tiax LLC; Cupertino, CA, 2008.

[23] A. Arteconi, C. Brandoni, D. Evangelista and F. Polonara, Life-cycle greenhouse gas analysis of LNG as a heavy vehicle fuel in Europe. Applied Energy, 87, pp. 2005-2013, 2010.

[24] T. Beer, T. Grant, D. Williams and H. Watson, Fuel-cycle greenhouse gas emissions from alternative fuels in Australian heavy vehicles. Atmospheric Environment, 36, pp. 753-763, 2002.

[25] W. L. Litzke and J. Wegrzyn, Natural gas as a future fuel for heavy-duty vehicles. SAE Technical paper series 2001-01-2067, 2001.

[26] D. Andress, T. D. Nguyen and S. Das, Reducing GHG emissions in the United States transportation. Energy for sustainable development, 15, pp. 117-136, 2011.

[27] D. Durbin and C. Malardier-Jugroot, Review of hydrogen storage techniques for on board vehicle applications. International journal of hydrogen energy, 38, pp. 14595-14617, 2013.

[28] L. De Simio, M. Gambino and S. Iannaccone, Possible transport energy sources for the future. Transport policy, 27, pp. 1-10, 2013.

[29] S. Yeh, An empirical analysis on the adoption of alternative fuel vehicles: The case of natural gas vehicles. Energy policy, 35, pp. 5865-5875, 2007.

[30] IANGV, "NGV global News," 26 septiembre 2006. www.ngvglobal.com 
[31] V. A. Peredel'skii, Y. V. Lastovskii, R. V. Darbinyan, A. I. Savitskii and A. A. Savitskii, Analysis of the desirability of replacing petroleum-based vehicel fuel with liquefied natural gas. Chemical and petroleum engineering, 41, no. 11-12, 2005.

[32] Lu, X.S., Gu, A.Z., Zhang, W.G., The development of LNG vehicles and the key technologies. In: The Sixth National Conference of Low Temperature and Refrigeration Engineering, China (in Chinese), 2003.

[33] Zhou, S.H., Chen, J.D., Lu, A.M., 2010. The choices of natural gas vehicle development mode in China's coastal regions. International Petroleum Economics 4, 14-19 (in Chinese), 2010.

[34] T. Korakianitis, A. Namasivayam and R. Crookes, Natural-gas fueled spark-ignition (SI) and compression-ignition (CI) engine performance and emissions. Progress in Energy and Combustion Science, 37, pp. 89-112, 2011.

[35] J. Merkisz, M. Jacyna, A. Merkisz-Guranowska and J. Pielecha, Exhaust emissions from modes of transport under actual traffic conditions. Proc. of the 1st International Conference on Energy Production and Management in the 21st Century, eds. C.A. Brebbia; E.R. Magaril and M.Y. Khodorovsky. WIT press: Southampton, 190, pp. 1139-1150, 2014.

[36] Petroleum Economist, China pushes natural gas as transport fuel, 2013. www.petroleum-economist.com/

[37] GASNAM, Asociación Española del Gas Natural para la Movilidad www.gasnam.es

[38] B. Paramo, El gas natural vehicular: una opción limpia y rentable para el transporte terrestre y marítimo. Proc. of El gas natural en el transporte terrestre y marítimo, Fundación Gas Natural Fenosa: Valencia, 2015.

[39] European Commission, LNG Blue Corridors, www.Ingbluecorridors.eu

[40] T. H. Zunder and J. N. Ibanez, Urban freight logistics in the European Union. European Transport|Trasporti Europei, 28, pp. 77-84, 2004.

[41] World Health Organization, WHO Regional Office for Europe, 01 Junio 2011. www.euro.who.int/ data/assets/pdf file/0008/136466/e94888.pdf

[42] K. Kijewska and B. G. Johansen, Comparative analysis of activities for more environmental friendly urban freight transport systems in Norway and Poland. Procedia - Social and Behavioral Sciences, 151, pp. 142-157, 2014.

[43] D. Wild, Integration of Freight in Urban Pricing Schemes. Proc. of the Second seminar of the IMPRINT-EUROPE; Implementing Reform on Transport Pricing: Identifying Mode-Specific issues, Brussels, 2002.

[44] J. Suksri and R. Raicu, Developing a conceptual framework for the evaluation of urban freight distribution initiatives. Procedia - Social and Behavioral Sciences, 39, pp. 321-332, 2012.

[45] H. Quak and M. de Koster, Urban Distribution: The Impacts of Different Governmental Time-Window Schemes. ERIM Report Series Research in Management, no. ERS-2006-053-LIS, 2006. 
[46] A. Stathopoulos, E. Valeri and E. Marcucci, Stakeholder reactions to urban freight policy innovation. Journal of Transport Geography, 22, pp. 34-45, 2012.

[47] J. Muñuzuri, P. Cortés and L. Onieva, City logistics in Spain: Why it might never work. Cities, 29, pp. 133-141, 2012.

[48] S. Zhang and A. Sobiesiak, The first and second law analyses of a portinjected, spark ignition engine fuelled with compressed natural gas. Journal of KONES Internal Combustion Engines, 1-2, 2002.

[49] R. Tilagone, G. Monnier and A. Chaouche, Development of a high efficiency, low emission SI-CNG bus engine. SAE Technical paper series, vol. 961080, 1996.

[50] A.-H. Kakaee and A. Paykani, Research and development of natural-gas fueled engines in Iran. Renewable and Sustainable Energy Reviews, 26, pp. 805-821, 2013.

[51] M. Abdelaal and A. Hegab, Combustion and emission characteristics of a natural gas-fueled diesel engine with EGR. Energy Conversion and Management, 64, pp. 301-312, 2012.

[52] Heraldo de Arangón Editora Digital, S.L.U, Simply invierte 2 millones de euros en su plataforma logística de Villanueva. Grupo Heraldo, 2403 2014. www.heraldo.es/noticias/aragon

[53] Mercedes-Benz España S.A, Mercedes-Benz España entrega la primera tractora Econic GNL a Acotral, 22 Diciembre 2009. www.mercedes.es /actualidad/noticias/news3.asp?NoNews $=1718$

[54] European Commission, Climate action: Reducing the carbon content of transport fuels, Press release, Brussels, 2014.

[55] MH21, Phase 1 Comprehensive report of research results, 11 March 2011. www.mh21japan.gr.jp/english/wp/wp-content/uploads/ca434ff85adf34a4 022f54b2503d86e92.pdf

[56] BGR, Energy Study 2014. Reserves, resources and availability of energy resources, 18. pp. 13, Hannover, 2014.

[57] GLE, Developing infrastructure to support the market for LNG as a fuel. Proc. of the European LNG Strategy, London, 2015. 